\title{
The influence of various sized zircaloy -4 oxidation products on hydrogen generation of the water solution by Co-60 gamma radiolysis
}

\author{
Yoshinobu MATSUMOTO*, Tatsuya SUZUKI*, Toru OGAWA**, \\ Masao INOUE*** and Ryuji NAGAISHI**** \\ *Nuclear System Safety Engineering, Nagaoka University of Technology \\ 1603-1 Kamitomioka, Nagaoka, Niigata, Japan \\ E-mail: matumoto@vos.nagaokaut.ac.jp \\ ${ }^{\star *}$ Extreme Energy-Density Research Institute, Nagaoka University of Technology \\ 1603-1 Kamitomioka, Nagaoka, Niigata, Japan \\ ${ }^{* * *}$ Nuclear Engineering Co., Ltd \\ 3129-29 Hibara Muramatsu, Tokai-mura, Naka-gun, Ibaraki, Japan \\ ${ }^{\star * \star *}$ Nuclear Engineering Research Collaboration Center, Japan Atomic Energy Agency \\ 2-4 Shirakata, Tokai-mura, Naka-gun, Ibaraki, Japan
}

Received: 31 October 2019; Revised: 12 March 2020; Accepted: 27 April 2020

\begin{abstract}
In this work, we have experimentally studied the effect of particle size of the oxidized zircaloy-4 on the observed yield of Hydrogen generation by Co-60 gamma radiolysis of water. The oxidation products were obtained by high-temperature oxidation of zircaloy- 4 under dry air atmosphere for 2 and 4 hours. We crushed them into various sizes from 3 to $484 \mu \mathrm{m}$ after the oxidation. The crushed particles of the product of 4 hours oxidation consisted of almost monoclinic zirconium oxide and the 2 hours oxidation product contained from 26 to $56 \%$ of tetragonal zirconium oxide. These particles had specific surface areas from 0.73 to $2.58 \mathrm{~m}^{2} / \mathrm{g}$ and band gaps $5.1 \mathrm{eV}$ all. The oxidation products of the weight fraction of $10 \%$ and distilled water were mixed into a $4 \mathrm{ml}$ glass vial to examine the Hydrogen generation by Co-60 gamma radiolysis. The experiments have presented that the observed hydrogen yield, $\mathrm{G}\left(\mathrm{H}_{2}\right)$ was increased by decreasing the median particle diameter of both the oxidation products. Especially, the $\mathrm{G}\left(\mathrm{H}_{2}\right)$ of water added the particles with 3 or $5 \mu \mathrm{m}$ became larger than that of only distilled water. This enhancement was not caused by the bandgap of the oxidation product. Calculated $\mathrm{G}\left(\mathrm{H}_{2}\right)$ per surface area of the oxidation product, $\mathrm{G}\left(\mathrm{H}_{2}\right) / \mathrm{S}$ was constant on all particle sizes. Furthermore, $\mathrm{G}\left(\mathrm{H}_{2}\right) / \mathrm{S}$ of the water added the oxidation products with the median particle diameter 3 or $5 \mu \mathrm{m}$ were larger than the commercial zirconium oxides $\left(\mathrm{m}-\mathrm{ZrO}_{2}, \mathrm{t}-\mathrm{ZrO}_{2}\right)$ whose median particle diameters are 3 $\mu \mathrm{m}$. In conclusion, Hydrogen generation of water by Co-60 gamma radiolysis was influenced by the particle size added into water. We have considered that the surface area of the oxidation product was the predominant factor of this effect because the $\mathrm{G}\left(\mathrm{H}_{2}\right)$ per specific surface area was constant regardless of particle size of the crushed oxidation products in this experiment.
\end{abstract}

Keywords : Hydrogen generation, Water radiolysis, Zircaloy-4, Oxidation, Particle size

\section{Introduction}

Radiolysis of water is a decomposition of water molecules by ionizing radiation. The water irradiated by the ionizing radiation like a gamma-ray generates ionized water molecules, electrons, and exciting water molecules. These chemical species can form hydroxyl radical, hydrogen molecule $\left(\mathrm{H}_{2}\right)$ and other molecules through the physical and chemical stages. The presence of some oxides influences the $\mathrm{H}_{2}$ amount generated by the water radiolysis (Petrik 
et al., 2001). Especially Zirconia $\left(\mathrm{ZrO}_{2}\right)$ and Urania are classed as the best ones which enhance the radiolytic $\mathrm{H}_{2}$ generation from the surface adsorbed water. After the severe accident of a nuclear power plant, a large amount of debris generated. This debris is assumed that have high radioactivity and includes some ceramics like an oxidation product of zircaloy-4 (zry-4) which used as a fuel cladding tube. (Journeau et al., 2017). We considered that the presence of the debris in water affects $\mathrm{H}_{2}$ generation of water radiolysis with ionizing radiations emitted from radioactive materials contained in the debris. We have oxidized the zry- 4 under various conditions and crushed them to investigate the effects of the oxidation products on the $\mathrm{H}_{2}$ generation by water radiolysis. The enhancement of $\mathrm{H}_{2}$ generation seemed to be dependent on either the specific surface area or the particle size of the oxidation product, but it was not certain which is the predominant factor (Matsumoto et al, 2015). The characterization of the aerosol source term emitted during the laser cutting of fuel debris assumes that the particle mass size distributions corresponding to particle aerodynamic diameters between 0.01 and $10 \mu \mathrm{m}$ (Porcheron et al, 2018). For this reason, we thought it necessary to investigate whether the hydrogen generation by radiolysis of water is influenced by the particle size of the oxidation product added to water.

In order to clarify whether the particle size of the oxidation product affects the $\mathrm{H}_{2}$ generation, we have oxidized zry-4 under two conditions and crushed them and classified to various sized particles. Then the effects of those particles on the $\mathrm{H}_{2}$ generation were examined in the Co-60 gamma radiolysis.

\section{Methods}

\subsection{Oxidation of zircaloy-4}

We have used a zry-4 plate (New Metals and Chemicals Ltd.) which dimensions are $0.914 \mathrm{~mm}$ in thickness by 100 $\mathrm{mm}$ in width and $100 \mathrm{~mm}$ in length. The zry-4 plate consists of $\mathrm{Sn} 1.44 \%, \mathrm{Fe} 0.20 \%, \mathrm{Cr} 0.10 \%, \mathrm{Al} 0.01 \%, \mathrm{Si} 0.007 \%$ and $\mathrm{Zr}$ balance. The plate was cut into pieces $(10 \times 20 \times 0.914 \mathrm{~mm})$ before oxidation. The pieces were placed on a quartz boat in a quartz reaction tube which was set into a ceramic electric tubular furnace (Asahi-rika Co., Ltd. ARF-50KC). The room in the quartz reaction tube was replaced with dry air (Shimakyu Co., Ltd.) which consists of $\mathrm{O}_{2} 21 \%$ and $\mathrm{N}_{2}$ balance. The oxidation products were oxidized from the zry-4 as follows: as one condition for obtaining almost monoclinic $\mathrm{ZrO}_{2}$, they were heated at $1100^{\circ} \mathrm{C}$ for 4 hours under $0.5 \mathrm{~L} / \mathrm{min}$ dry air (oxidation product $\mathrm{M}$ ); the other condition for including tetragonal $\mathrm{ZrO}_{2}$, they were heated at $1100^{\circ} \mathrm{C}$ for 2 hours under $0.05 \mathrm{~L} / \mathrm{min}$ dry air (oxidation product T). The furnace temperature was raised to $1100{ }^{\circ} \mathrm{C}$ by a rate of $10^{\circ} \mathrm{C} / \mathrm{min}$ and then held at $1100{ }^{\circ} \mathrm{C}$ for 2 or 4 hours. Thereafter, the furnace was cooled to room temperature over 5 hours. The dry air flowed in the quartz reaction tube until the pieces were cooled around room temperature.

\subsection{Characterization of the oxidation products}

The oxidized plates were crushed using an agate mortar well and classified with five stainless steel sieves. The sieve openings were 300, 150, 75, 40 and $20 \mu \mathrm{m}$. Particle size distribution measurements of the classified groups were performed by a laser scattering particle size distribution analyzer (HORIBA Ltd. LA-960) using a wet method. X-ray Diffraction (XRD) of the oxidation products were analyzed by a powder diffractometer (Rigaku Co. Miniflex600) at $40 \mathrm{kV}$ and $15 \mathrm{~mA}$, using $\mathrm{Cu}-\mathrm{K} \alpha$ radiation. The phase composition was obtained with Rietveld analysis module of Integrated X-ray powder diffraction software (Rigaku Co. PDXL2). The specific surface area of the particle was calculated by Brunauer-Emmet-Teller (BET) method using adsorption isotherms with $\mathrm{H}_{2} \mathrm{O}$ at $298.15 \mathrm{~K}$ with BELSORP-max (BEL Japan Inc.). An UV-Vis spectrometer (JASCO Co. V-660) with an integration sphere (JASCO Co. ISV-722) was used for the diffuse reflectance spectra measurement. The bandgap of the particle was determined from the spectra using Tauc plot.

\subsection{Water Radiolysis}

The particles of the oxidation products and distilled water (SOGO Laboratory Glass Works Co.,Ltd.) were used for preparing samples for water radiolysis. The distilled water was placed under room air until the $\mathrm{pH}$ of the water stabilized by absorption of carbon dioxide $\left(\mathrm{CO}_{2}\right)$. The distilled water was contacted with the particles in $4 \mathrm{ml}$ glass 
vials (Chromacol, Ltd. 4-SV). The amount of the particles was calculated to the weight fraction to be $10 \%$. The height of the mixture solution was adjusted to $1 \mathrm{~cm}$ in the vial. The mixture solution was not deaerated. The vial containing the mixture was stirred at $3000 \mathrm{rpm}$ for 2 minutes using a vortex mixer (ELMI, V-3 SkyLine Vortex Mixer) after sealed with a septum. There were the aqueous phase and the air phase in the vial. The sample of only distilled water was also prepared using the above method for control. The $\mathrm{pH}$ value of the water solution was measured by a pH meter (HORIBA Ltd. D-12).

The effects of those particles of oxidation products on the $\mathrm{H}_{2}$ generation were examined in the Co- 60 gamma radiolysis. The sample vials were irradiated with a gamma-ray at an average dose rate of 4-5 kGy/h by a Co-60 source in the National Institutes for Quantum and Radiological Sciences and Technology. These samples and chemical dosimeters $\left(1 \mathrm{mM} \mathrm{K} \mathrm{Cr}_{2} \mathrm{O}_{7} / 0.4 \mathrm{M} \mathrm{H}_{2} \mathrm{SO}_{4}\right)$ were irradiated simultaneously for 30, 60, 90 and 120 minutes at room temperature. After the irradiation, the sample vials were stirred at $3000 \mathrm{rpm}$ for 2 minutes using a vortex mixer.

The absorbed doses of the samples were calculated from the measurement of absorbance of the chemical dosimeter at 350nm using a UV-Visible spectrometer (JASCO Co. V-550). $\mathrm{H}_{2}$ gas concentrations of the air phase in the vials were measured with a gas chromatograph system (GL Sciences Inc. GC-3200W) equipped with a thermal detector (TCD) and a molecular sieve column using argon (Ar) carrier gas. The detected $\mathrm{H}_{2}$ peak was calibrated with the standard $\mathrm{H}_{2} /$ Ar gases. $\mathrm{H}_{2}$ yield of water radiolysis is defined by the G-Value expressed in amount of $\mathrm{H}_{2}$ per Joule of absorbed dose. In this study, the observed $\mathrm{H}_{2}$ yield, $\mathrm{G}\left(\mathrm{H}_{2}\right)(\mathrm{mol} / \mathrm{J})$, was calculated from the proportionality of absorbed dose $(\mathrm{Gy}=\mathrm{J} / \mathrm{kg})$ and $\mathrm{H}_{2}$ production $(\mathrm{mol} / \mathrm{kg})$ for all samples.

\section{Results}

\subsection{Particle size of the oxidation products}

Five groups of the particles with different particle sizes were obtained using agate mortar and stainless steel sieve for each oxidation products. The particle size distributions of the groups of the oxidation product $\mathrm{M}$ are shown in Fig.1. All groups had a main-peak and some groups had a small sub-peak. So we used the median diameter instead of a mode diameter as a representative diameter of the particles. The median particle diameter means a value of particle diameter at $50 \%$ of the cumulative volume distribution based on the volume measured with a laser scattering type particle size measuring instrument. The median particle diameters were $3,63,134,245$, and $473 \mu \mathrm{m}$ and were labeled the oxidation product M1, M2, M3, M4, and M5 respectively. Using the same method, the particles of the oxidation product $\mathrm{T}$ were classified 5, 67, 133, 285, and $484 \mu \mathrm{m}$ and were labeled the oxidation product T1, T2, T3, T4, and T5.

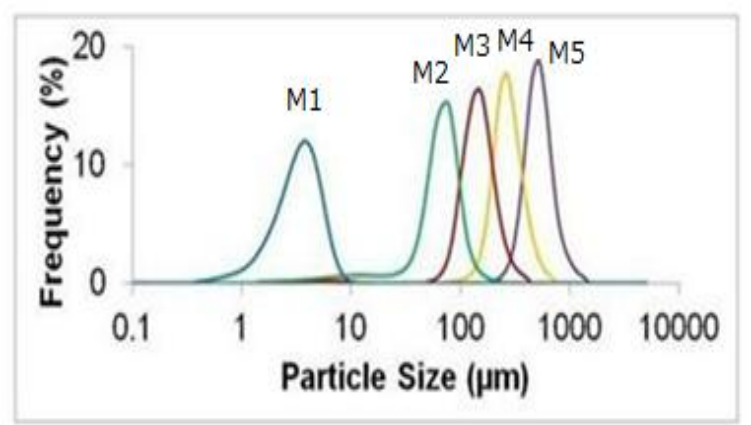

Fig.1 The particle size distributions of the groups of the oxidation product $\mathrm{M}$

\subsection{Phase composition of the oxidation products}

Figure 2 gives the XRD patterns of the oxidation products on the sieves. The phase composition of the oxidation products $\mathrm{M} 1$ to $\mathrm{M} 5$ consisted of almost monoclinic $\mathrm{ZrO}_{2}$, and the oxidation product $\mathrm{T} 1$ to $\mathrm{T} 5$ contained from $26 \%$ to $56 \%$ of tetragonal $\mathrm{ZrO}_{2}$ and at most $10 \%$ of $\mathrm{ZrN}$. 

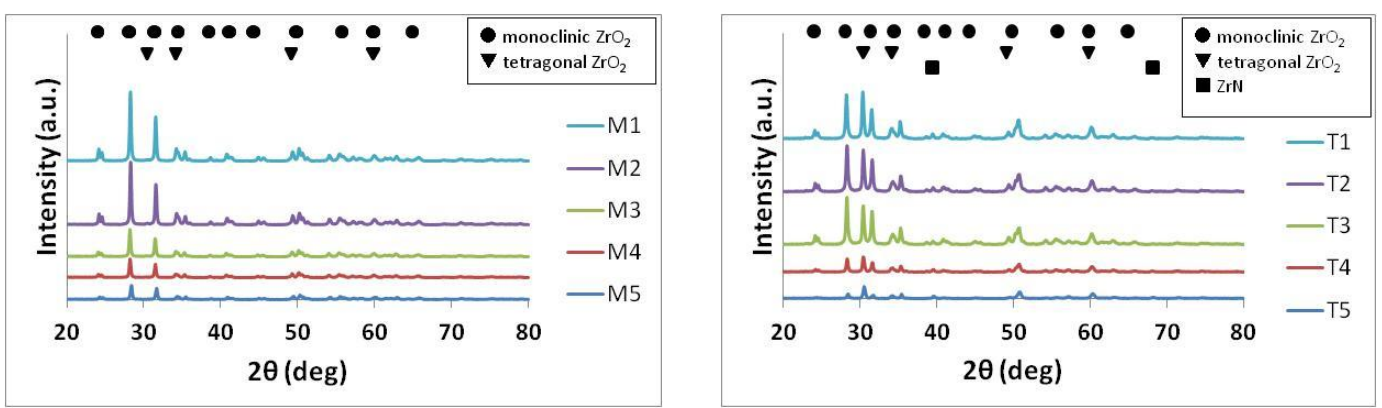

Fig. 2 XRD patterns of each group of the oxidation products of zircaloy-4.

\subsection{Specific surface area and bandgap of the oxidation products}

The specific surface areas of the particles were from 0.73 to $2.58 \mathrm{~m}^{2} / \mathrm{g}$. The particles classified by the sieve with $40 \mu \mathrm{m}$ sieve opening were not able to measure the specific surface area because the amounts of samples were not enough. The variation of the specific surface area with the median particle diameter of the oxidation products is shown in Fig.3. As expected, decreasing the median particle diameter by grind increased the specific surface area of the particles.

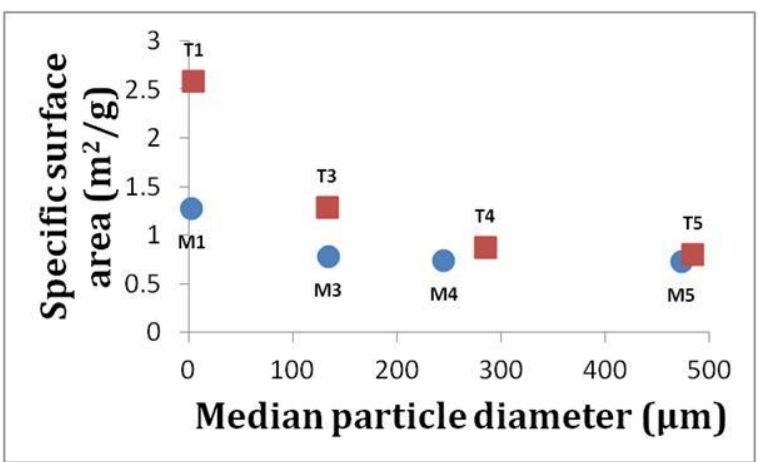

Fig. 3 The relationships between the median particle diameter and the specific surface area of the oxidation products.

We summarized the values of the particle size, the phase components, the specific surface area, and the bandgap of the oxidation products in Table 1. Our obtained bandgaps of all oxidation products were same values. According to reference (Ciuparu et al., 2000), the bandgaps are not varied from a quantum size effect or from a difference of crystal structure under in the case of nanometer-sized $\mathrm{ZrO}_{2}$ particle. Thus, we infer the bandgaps of the oxidation product $\mathrm{M}$ and $\mathrm{T}$ were not changed by crushing cause the same reason.

Table 1 The features of the oxidation products.

\begin{tabular}{|c|c|c|c|c|c|c|}
\hline \multirow{2}{*}{$\begin{array}{l}\text { Oxidation } \\
\text { Product }\end{array}$} & \multirow[b]{2}{*}{$\begin{array}{l}\text { Median Particle } \\
\text { Diameter }[\mu \mathrm{m}]\end{array}$} & \multicolumn{3}{|c|}{ Phase composition } & \multirow{2}{*}{$\begin{array}{c}\text { Specific } \\
\text { Surface Area } \\
{\left[\mathrm{m}^{2} / \mathrm{g}\right]} \\
\end{array}$} & \multirow[b]{2}{*}{$\begin{array}{c}\text { Band gap } \\
{[\mathrm{eV}]}\end{array}$} \\
\hline & & $\begin{array}{c}\text { Monoclinic } \\
\mathrm{ZrO}_{2}[\%]\end{array}$ & $\begin{array}{c}\text { Tetragonal } \\
\mathrm{ZrO}_{2}[\%]\end{array}$ & $\mathrm{ZrN}[\%]$ & & \\
\hline M1 & 3 & 99 & 1 & 0 & 1.27 & 5.1 \\
\hline M2 & 63 & 98 & 2 & 0 & - & 5.1 \\
\hline M3 & 134 & 98 & 2 & 0 & 0.78 & 5.1 \\
\hline M4 & 245 & 99 & 1 & 0 & 0.74 & 5.1 \\
\hline M5 & 473 & 100 & 0 & 0 & 0.73 & 5.1 \\
\hline $\mathrm{T} 1$ & 5 & 72 & 26 & 2 & 2.58 & 5.1 \\
\hline $\mathrm{T} 2$ & 67 & 55 & 40 & 5 & - & 5.1 \\
\hline $\mathrm{T} 3$ & 133 & 58 & 37 & 5 & 1.28 & 5.1 \\
\hline $\mathrm{T} 4$ & 285 & 48 & 44 & 8 & 0.87 & 5.1 \\
\hline $\mathrm{T} 5$ & 484 & 34 & 56 & 10 & 0.80 & 5.1 \\
\hline
\end{tabular}




\section{4 $\mathrm{H}_{2}$ yield by water radiolysis in presence of the oxidation products}

The $\mathrm{pH}$ value of the distilled water used in this experiment was 5.7. The mixture solutions with the oxidation product $\mathrm{M}$ or $\mathrm{T}$ before gamma irradiation were 6.2 and 6.0 respectively. All pH values were close to 6.

We show in Fig.4, the dependence of the $\mathrm{G}\left(\mathrm{H}_{2}\right)$ on the median particle diameter of the oxidation product in the mixture. The $\mathrm{G}\left(\mathrm{H}_{2}\right)$ increased with the decrease of the median particle diameter of both the oxidation products. The $\mathrm{G}\left(\mathrm{H}_{2}\right)$ of only distilled water was $1.8 \mathrm{E}-8 \mathrm{~mol} / \mathrm{J}$. In the case of the oxidation products with the median particle diameter was 3 or $5 \mu \mathrm{m}$ were added, $\mathrm{G}\left(\mathrm{H}_{2}\right)$ became larger than that of only distilled water. However, this enhancement of the solution with the oxidation products of some large particles was the same or less than the one of only distilled water. Petrik et al. (2001) reported that $\mathrm{ZrO}_{2}$ enhances the radiolytic $\mathrm{H}_{2}$ generation from the surface adsorbed water. This difference may be caused by the experimental condition. We used the oxidation product of zry-4 and immersed in the water but Petrik et al. (2001) used $\mathrm{H}_{2} \mathrm{O}$ adsorbed on the surface of the oxide powder.

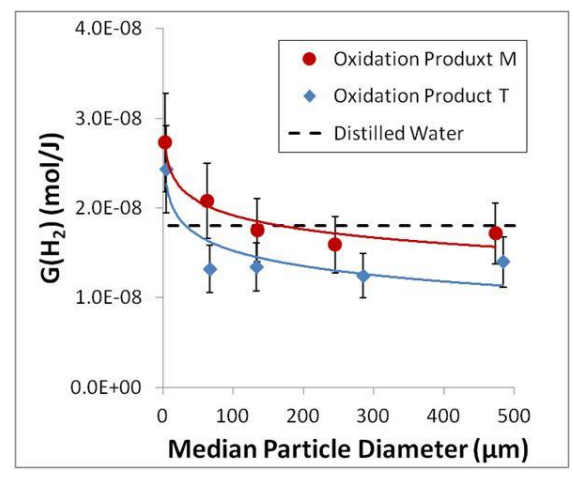

Fig. 4 The dependence of the $\mathrm{G}\left(\mathrm{H}_{2}\right)$ on the median particle diameter of the oxidation product.

\section{Discussions}

\subsection{Effect of the particle size on the $\mathrm{H}_{2}$ generation}

In our previous study, the $\mathrm{H}_{2}$ generation of water radiolysis was enhanced by added the oxidation product of zry-4. In order to clarify whether the particle size of the oxidation product affects the $\mathrm{H}_{2}$ generation, five sizes of the oxidation product particles were prepared and used the experiment of water radiolysis. The $\mathrm{G}\left(\mathrm{H}_{2}\right)$ were substantially increased by decreasing the median particle diameter of both the oxidation products (Fig.4). Thus the particle size of the oxidation products influences the $\mathrm{H}_{2}$ generation. Especially, the $\mathrm{G}\left(\mathrm{H}_{2}\right)$ of water added the 3 to $5 \mu \mathrm{m}$ particles were strongly enhanced.

Regarding the effect of oxide particle dispersed in water on hydrogen evolution by water radiolysis, it has reported using nanoparticles of $\mathrm{TiO}_{2}$ and $\mathrm{Al}_{2} \mathrm{O}_{3}$ (Seino et al., 2001,). It has indicated that the hydrogen yield was enhanced mainly by the effective surface area of the nanoparticles regardless of chemical species. The surface area of the oxidation products of zry-4 also effects on the $\mathrm{H}_{2}$ yield by water radiolysis because decreasing the median particle diameter tends to increase the specific surface area of the particles in Fig.3.

Figure 5 represent the $\mathrm{G}\left(\mathrm{H}_{2}\right)$ per surface area, calculated by using the specific surface area and added weight of the oxidation products, were plotted against the median particle diameter of the particles. Figure 5 indicates the $\mathrm{G}\left(\mathrm{H}_{2}\right) / \mathrm{S}$ of the oxidation product was constant regardless of particle size. Therefore we considered the effect of particle size of the oxidized zry-4 on $\mathrm{G}\left(\mathrm{H}_{2}\right)$ was caused by the surface area of the particle. 


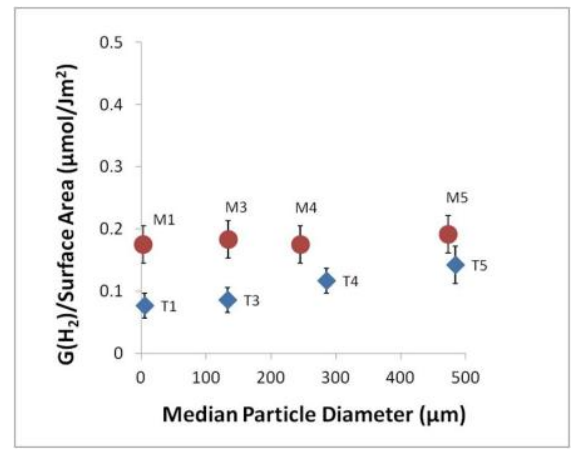

Fig. 5 Relationship between the $\mathrm{G}\left(\mathrm{H}_{2}\right) / \mathrm{S}$ and the median particle diameter of the oxidation products

\subsection{Difference in $\mathrm{H}_{2}$ generation between the oxidation products and two commercial zirconium oxides}

The $\mathrm{G}\left(\mathrm{H}_{2}\right) / \mathrm{S}$ of the oxidation product $\mathrm{M}$ was larger than that of the oxidation product $\mathrm{T}$ in all groups. These particles had a similar particle size, specific surface area, and bandgap. The difference of these oxidation products was the phase composition. The oxidation product $\mathrm{T}$ had much tetragonal $\mathrm{ZrO}_{2}$ than that of the oxidation product $\mathrm{M}$. The oxidation product $\mathrm{M}$ had a small amount of $\mathrm{ZrN}$ but it has been confirmed that $\mathrm{ZrN}$ in pure water did not produce $\mathrm{H}_{2}$ (Heshikiri et al, 2014). The $\mathrm{H}_{2}$ production from gamma radiolysis of water containing 60 nanometer-sized tetragonal $\mathrm{ZrO}_{2}$ and monoclinic $\mathrm{ZrO}_{2}$ has been reported (Laverne, 2005). The literature showed the $\mathrm{H}_{2}$ yield of water containing tetragonal $\mathrm{ZrO}_{2}$ particles significantly increased than the monoclinic form. In our previous study which used two commercial zirconium oxides indicated that the $\mathrm{G}\left(\mathrm{H}_{2}\right)$ of yttria-stabilized tetragonal zirconia $\left(\mathrm{t}-\mathrm{ZrO} \mathrm{r}_{2}\right)$ was larger than monoclinic zirconia $\left(\mathrm{m}-\mathrm{ZrO}_{2}\right)$. The $\mathrm{G}\left(\mathrm{H}_{2}\right)$, median particle diameter, and specific surface area of $\mathrm{m}-\mathrm{ZrO} \mathrm{r}_{2}$ were $2.1 \mathrm{E}-08 \mathrm{~mol} / \mathrm{J}, 3 \mu \mathrm{m}$, and $19.6 \mathrm{~m}^{2} / \mathrm{g}$ and these of $\mathrm{t}-\mathrm{ZrO}_{2}$ were $4.2 \mathrm{E}-08 \mathrm{~mol} / \mathrm{J}, 3 \mu \mathrm{m}$, and $63.2 \mathrm{~m}^{2} / \mathrm{g}$ (Matsumoto et al, 2015). However, in the experiments with water containing two different oxidation products of zry-4, the $G\left(\mathrm{H}_{2}\right)$ of the oxidation product $T$ never exceeded the oxidation product $M$. We have calculated and compared the $G\left(H_{2}\right) / S$ of the oxidation products and two commercial zirconium oxides. Figure 6 shows the $\mathrm{G}\left(\mathrm{H}_{2}\right) / \mathrm{S}$ of the oxidation products with the 3 or $5 \mu \mathrm{m}$ particle diameters are larger than commercial zirconium oxides $\left(\mathrm{m}-\mathrm{ZrO} \mathrm{r}_{2}, \mathrm{t}-\mathrm{ZrO} \mathrm{O}_{2}\right)$. The large differences were observed in $\mathrm{G}\left(\mathrm{H}_{2}\right) / \mathrm{S}$ between the oxidation products of zry-4 and commercial zirconium oxides. This result suggests the enhancement of the $\mathrm{H}_{2}$ generation is affected by the difference $\mathrm{ZrO}_{2}$ structures in the commercial zirconium oxide and in the oxidation product of zry-4.

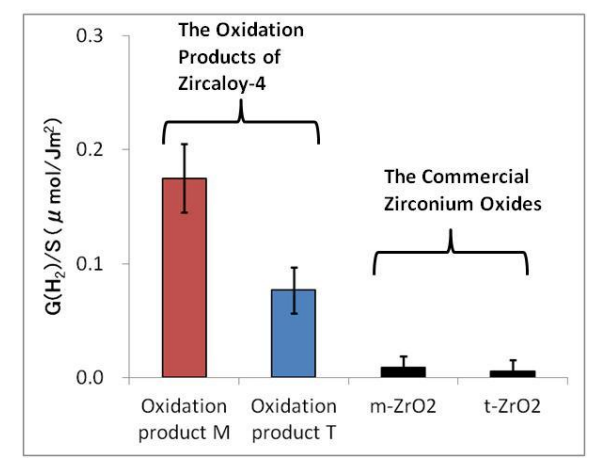

Fig. 6 Comparison of the $\mathrm{G}\left(\mathrm{H}_{2}\right) / \mathrm{S}$ of the oxidation products, $\mathrm{m}-\mathrm{ZrO}_{2}$, and $\mathrm{t}-\mathrm{ZrO}_{2}$.

\subsection{Effect of $\mathrm{pH}$ on the $\mathrm{H}_{2}$ generation}

The distilled water had become weak acid ( $\mathrm{pH}$ 5.7) by absorption of $\mathrm{CO}_{2}$. The $\mathrm{pH}$ values were increased to 6.2 or 6.0 by adding the oxidation product $\mathrm{M}$ or $\mathrm{T}$ respectively. In the case of the commercial zirconium oxides, the $\mathrm{pH}$ values of the mixture solutions were 5.4 by the $\mathrm{m}-\mathrm{ZrO}_{2}, 7.8$ by the $\mathrm{t}-\mathrm{ZrO}_{2}$. 


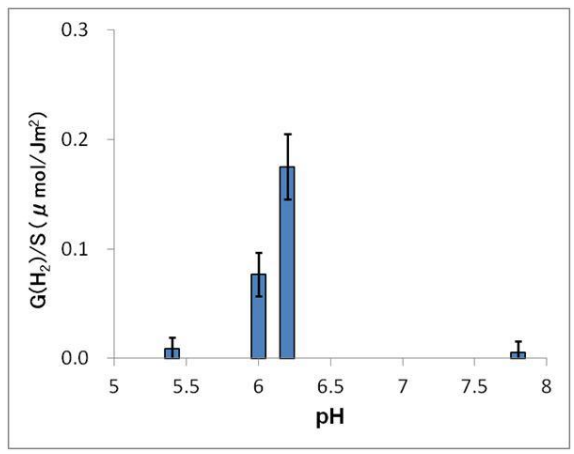

Fig. 7 Relationship between the $\mathrm{G}\left(\mathrm{H}_{2}\right) / \mathrm{S}$ and the $\mathrm{pH}$ of the mixture solutions.

It has been reported that the primary yield of $\mathrm{H}_{2}$ on water radiolysis is almost constant in the pH value between 3 and 11 (Ferradini and Jay-Gerin, 2000). However, Fig. 7 shows the $\mathrm{G}\left(\mathrm{H}_{2}\right) / \mathrm{S}$ has maximum value around $\mathrm{pH} 6$. This enhancement effect may be due to the some structural change in $\mathrm{ZrO}_{2}$ or some substance adsorbed on $\mathrm{ZrO}_{2}$.

Since the observed bandgaps of the oxidation products of zry-4 were same values, it could not explain the enhancement of $\mathrm{H}_{2}$ generation.

The $\mathrm{H}_{2}$ formation from gamma radiolysis of water containing nanometer-sized $\mathrm{ZrO}_{2}$ was dependent on the crystalline structure of the particle has been reported (Laverne, 2005). It has also been reported that a powdered ultrapure grade $\mathrm{ZrO}_{2}$ crystal doped with quite small concentration $\left(\sim 0.1 \%\right.$ mass.) $\mathrm{Nb}^{5+}$ significantly suppressed the radiolysis of water (Petrik et al., 2001). The $\mathrm{t}-\mathrm{ZrO}_{2}$ which was used in this study stabilizes the tetragonal structure of $\mathrm{ZrO}_{2}$ with yttria ion $\left(\mathrm{Y}^{3+}\right)$. It has been reported that the tetragonal structure of $\mathrm{ZrO}_{2}$ is also stabilized by nitrogen incorporate (Lerch and Rahauser, 1997). In our study, the oxidation products of zry-4 under dry air atmosphere might stabilize the tetragonal structure with nitrogen ion $\left(\mathrm{N}^{3-}\right)$. We thought that the reason why $\mathrm{G}\left(\mathrm{H}_{2}\right) / \mathrm{S}$ of the oxidation product of zry-4 is stronger than that of $\mathrm{m}-\mathrm{ZrO}_{2}$ or $\mathrm{t}-\mathrm{ZrO}_{2}$ is related to the difference of the mechanism of stabilization, but we need further investigation for clarification.

\section{Conclusions}

We prepared the oxidation products of zry-4 and crushed them to particles with various sizes from 3 to $484 \mu \mathrm{m}$. The observed $\mathrm{H}_{2}$ yield from the water added the particle by the Co-60 gamma radiolysis was increased as the particle size became smaller. In addition, when the oxidation products with the median particle size was 3 or $5 \mu \mathrm{m}$ was added, $\mathrm{G}\left(\mathrm{H}_{2}\right)$ became larger than that of only distilled water. The predominant factor of this enhancement of $\mathrm{H}_{2}$ generation is the surface area because $\mathrm{G}\left(\mathrm{H}_{2}\right) / \mathrm{S}$ was constant regardless of particle size. The reason for the difference of $\mathrm{G}\left(\mathrm{H}_{2}\right) / \mathrm{S}$ between two oxidation products of zry-4 couldn't be cleared in this experiment.

\section{Acknowledgments}

A part of this study was performed on the re-entrustment from the LWR hydrogen safety program of the Japan Atomic Energy Agency, which is funded by the Ministry of Economy, Trade and Industry..

\section{References}

Ciuparu, D., Ensuque, A., Shafeev, G. and Bozon-Verduraz, F., Synthesis and apparent bandgap of nanophase zirconia, Journal of Material Science Letters, Vol.19 (2000) pp931-933.

Ferradini, C. and Jay-Gerin, JP., The effect of pH on water radiolysis: a still question. A mini review, Research on Chemical Intermediates, Vol.26, No.6 (2000), pp549-565.

Heshikiri, T., Do TMD., Nagaishi, R. and Ogawa, T., Radiolysis of water suspending oxidized powder of metal zirconium, Paper presented at: The Annual Meeting of the Atomic Energy Society of Japan, Mar. 26-28, Tokyo, Japan (2014), Japanese. 
Journeau, C., Monneris, J., Tormos, B., Brissonneau, L., Excoiffier, E., Testud, V., Chagnot, C. and Roulet, D., Fabricating Fukushima Daiichi in-vessel and ex-vessel fuel debris simulants for the development and qualification of laser cutting technique, Proc. 8th European Review Meeting on Severe Accident Research (ERMSAR), Warsaw, Poland, May 16-18 (2017).

Laverne, J. A., $\mathrm{H}_{2}$ Formation from the Radiolysis of Liquid Water with Zirconia, The Journal of Physical Chemistry B, 109 (2005), pp.5395-5397.

Lerch, M. and Rahauser, O., Subsolidus phase relationships in the $\mathrm{ZrO}_{2}$-rich part of the $\mathrm{ZrO}_{2}-\mathrm{Zr}_{3} \mathrm{~N}_{4}$ system, Journal of Materials Science, Vol.32 (1997), pp1357-1363.

Matsumoto, Y., Do, T.-M.-D., Inoue, M., Nagaishi, R. and Ogawa, T., Hydrogen generation by water radiolysis with immersion of oxidation products of Zircaloy-4, Journal of Nuclear Science and Technology, Vol.52, No.10 (2015), pp. 1303-1307.

Petrik, N. G., Alexandrov, A. B. and Vall, A. I., Interfacial Energy Transfer during Gamma Radiolysis of Water on the Surface of $\mathrm{ZrO}_{2}$ and Some Other Oxides, The Journal of Physical Chemistry B, 105 (2001), pp.5935-5944.

Porcheron, E., Peillon, S., Gelain, T., Chagnot, C., Journeau, C., Excoffier, E., Testud, V. and Roulet, D., Fukushima Dai-ichi fuel debris retrieval analysis of aerosol emission and dispersion during simulants laser cutting, Proc. Dismantling Challenges: Industrial Reality, Prospects and Feedback Experience, France (DEM 2018), Avignon, October 22-24 (2018).

Seino, S., Yamamoto, T., Fujimoto, R., Hashimoto, K., Katsura, M., Okuda, S. and Okitsu, K., Enhancement of Hydrogen Evolution Yield from Water Dispersing Nanoparticles Irradiated with Gamma-Ray, Journal of Nuclear Science and Technology, Vol.38, No.8 (2001), pp. 633-636. 